\title{
Verifying the reliability of historical sources through an archaeometric study
}

Simona Quartieri ${ }^{1}$, Giuseppe Sabatino ${ }^{1}$, Marcella Di Bella ${ }^{1}$, Alessandro Tripodo ${ }^{1}$, Francesco Italiano ${ }^{2}$, Agostino Giuliano ${ }^{3}$ ${ }^{1}$ MIFT Department, University Of Messina (Italy), Messina S. Agata, Italy, ${ }^{2}$ Istituto Nazionale di Geofisica e Vulcanologia, Palermo, Italy, ${ }^{3}$ Museo Regionale di Messina, Viale della Libertà 465., Messina, Italy

E-mail: squartieri@unime.it

During the past centuries, several historic buildings of Messina (Sicily, Italy) - as well as of some villages in the province were widely decorated using a typical black-green stone. Important examples are visible, for instance, in the façade decorations of the Messina Cathedral (Fig. a,b). After 1908 Messina earthquake (Fig, c), remains of collapsed historical buildings were saved and are now stored in the City Regional Museum. From these remains - coming from different known locations - some stone samples (Fig. b) used for floor and façade decorations (XIIIth - XIVth century) were selected for this study, in order to define their origin provenance.

The Historical Notary Archives of Messina and Palermo retain several documents reporting legal transactions and purchasing of decorative stones. Concerning the provenance of the materials under study, these documents indicate the quarries located in the nearby of the Larderia Village (Peloritani Mt., about $8 \mathrm{~km}$ South of Messina) and in the close Zafferia Village. Here, metamorphic amphibolitic rocks, belonging to the Aspromonte Unit outcrop, are present.

To verify the reliability of these historical sources, and to provide more precise information on this decorative material, an archeometric characterization of some micro-fragments was carried out through a multidisciplinary approach, based on mineralogical/petrographic, diffractometric and chemical analysis.

The investigated specimens resulted to be metabasites showing pseudomorphic and vein textures, with relicts of olivine replaced by serpentine and orthopyroxene, mostly altered to bastite. Pseudomorphic minerals are serpentine (lizardite and crisotyle), magnetite, amphibole (tremolite-actinolite serie) and chlorite (talc-chlorite). These results demonstrate that the analyzed green stones cannot belong to the amphibolites outcrop of the Peloritani Mountains. Otherwise, they show mineralogical and petrographic features very similar to those of "verde Calabria", a rock typology largely exposed in the Northern Calabria area - belonging to the ophiolitic series - and widely used in the last century as building material [1].

Sabatino, G., Di Bella, M., Quartieri, S., Giuliano, A., Italiano, F., Marcianò, F., Tripodo, A., \& Romano, D. (2016) Verifying the reliability of historical sources through a mineralogical and petrographic approach: the case of the "black-green stone" from the Messina Cathedral (Sicily, Italy). Mediterranean Archaeology and Archaeometry 16(3), 79-91.

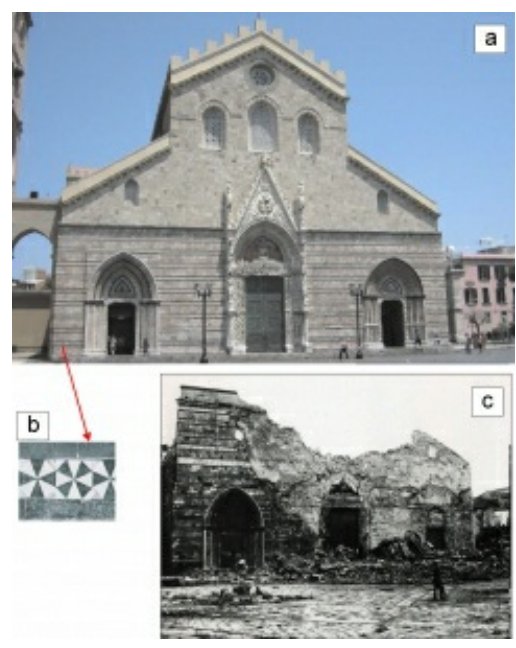

Keywords: Archaeometry, Messina Cathedral, green decorative stones 